\title{
An Assessment of the AGA and CCFA Quality Indicators in a Sample of Patients Diagnosed with Inflammatory Bowel Disease
}

\author{
Joseph Tkacz, MS; Brenna L. Brady, PhD; Roxanne Meyer, PharmD; \\ Jennifer H. Lofland, PharmD, MPH, PhD; Charles Ruetsch, PhD; and Nayantara Coelho-Prabhu, MBBS
}

\section{ABSTRACT}

BACKGROUND: Inflammatory bowel disease (IBD) is a chronic relapsing disease characterized by activation of the mucosal immune system and inflammation of the gastrointestinal tract. Management of IBD places a significant burden on the health care system because of the complexity of treatment, variability in patient outcomes, and chronic nature of the disease.

OBJECTIVE: To investigate the American Gastroenterological Association (AGA) and Crohn's and Colitis Foundation of America's (CCFA) quality measurement sets in a sample of IBD patients.

METHODS: Fourteen quality measures were restated for application to a claims database and calculated using Optum Clinformatics DataMart database. Selected measures were calculated over calendar year 2011.

RESULTS: Performance measures ranged from $0.4 \%$ for AGA measure 9 , prophylaxis for venous thromboembolism, to $66.9 \%$ for AGA measure 8 , testing for Clostridium difficile. CCFA outcome measures ranged from $0.6 \%$ qualifying for CCFA 010, report of fecal incontinence, to $32.9 \%$ for CCFA 01 , prednisone usage. In addition to Clostridium difficile testing, the use of appropriate corticosteroid-sparing therapy $(51.1 \%)$ and testing for latent tuberculosis before initiating anti-tumor necrosis factor therapy $(45.0 \%)$ were the highest achieved measures.

CONCLUSIONS: This is the first examination of IBD quality measures using administrative claims. Rates of achievement across measures were variable and likely affected by the ability to calculate certain measures with claims data. Future studies should further examine measurement of IBD quality indicators in claims data to assess the validity of claims-based analyses and to ascertain whether measure attainment translates into better overall health or IBD-related outcomes.

J Manag Care Spec Pharm. 2015;21(11):1064-76

Copyright $\odot 2015$, Academy of Managed Care Pharmacy. All rights reserved.

\section{What is already known about this subject}

Inflammatory bowel disease (IBD) is becoming more prominent in developing nations and is increasing in incidence and prevalence worldwide.

IBD patients incur 3- to 5-fold higher annual medical costs than individuals not suffering from IBD; in 2008, this cost augmentation translated to over $\$ 6$ billion in medical costs for IBD patients in the United States.
Because of the lack of available quality metrics and ongoing measurement, the quality of IBD care remains unknown and/or variable; consequently, the American Gastroenterological Association (AGA) and Crohn's and Colitis Foundation of America (CCFA) have released quality measure sets designed to improve the quality of IBD care.

\section{What this study adds}

This study investigated the rate of achievement for 2 sets of quality measures in a national sample of commercially insured patients diagnosed with IBD.

This is the first known examination of the AGA and CCFA quality measures assessed through administrative claims data.

Rates of measure achievement were highly variable and ranged from $0.4 \%$ to $66.9 \%$, with some measures achieving at lower than expected rates; these low rates are likely a reflection of the inherent difficulty and limitations using administrative claims data to calculate these measures.

T nflammatory bowel disease (IBD) is a complex group of autoimmune disorders characterized by chronic activation of the mucosal immune system and inflammation of the gastrointestinal tract. ${ }^{\text {}}$ Ulcerative colitis (UC), which affects the colon and rectum, and Crohn's disease (CD), which can affect any portion of the gastrointestinal tract, are the 2 primary diagnoses of IBD. ${ }^{2}$ A disease previously found mostly in Westernized nations, IBD is becoming more prominent in developing nations and is increasing in incidence and prevalence worldwide. ${ }^{3}$ In the United States alone, there are approximately 1 million prevalent cases of IBD, with 30,000 incident cases annually. ${ }^{4,5}$ The chronic inflammatory cascade present in IBD leads to tissue damage, loss of barrier function in the gut epithelium, and disease progression. ${ }^{1}$ The etiology of IBD remains unknown, but environmental, genetic, and epigenetic factors play a role in susceptibility and disease severity. ${ }^{6-9}$

IBD is a chronic relapsing and remitting disease; therefore, treatment efforts are aimed at achieving prolonged periods of remission. ${ }^{10-12}$ Rates of remission differ between $C D$ and UC and are impacted by medication regimens and patient-specific factors. ${ }^{13-15}$ Relapse from a state of remission is also more likely with extended periods of time off treatment. ${ }^{14}$ It is estimated that approximately $50 \%$ of IBD patients are in remission at any 
time, but $1 \%$ of UC and $25 \%$ of CD patients exhibit continuously active disease. ${ }^{16,17}$ Because of the lifelong nature of this disease and the relatively young age of onset, treatment for IBD can place a significant burden on the health care system. ${ }^{18}$ IBD patients incur 3- to 5-fold higher annual medical costs than individuals not suffering from IBD. ${ }^{19,20}$ In 2008, this cost augmentation translated to over $\$ 6$ billion in medical costs for IBD patients in the United States. ${ }^{19}$ The indirect cost burden of IBD is substantial and mainly accounted for by the inability to maintain employment and by reduced psychological well being. ${ }^{18,21}$ Only one third of IBD patients with active symptoms in the preceding year report being part of the labor force; indirect costs due to lost time in the workforce are estimated to amount to over $\$ 5.5$ billion. ${ }^{22,23}$ Even by more conservative estimates, the indirect costs are still substantial and account for an additional loss of $\$ 738$ per capita for IBD patients, leading to total indirect costs of $\$ 249$ million. ${ }^{24}$

Increased quality in health care, through initiation of proper treatment pathways and proper monitoring of patient health and well being, can result in better control of IBD symptoms and disease progression, leading to increased quality of life and reduced costs. ${ }^{18,25,26}$ In the case of IBD, the difficulty of diagnosis, range of symptoms, chronic nature, and potential for severe complications are factors that complicate treatment strategies and affect the rate of positive outcomes. ${ }^{27,28}$ Because chronic illnesses such as IBD are lifelong and require increased use of health care services, outcomes are likely to be affected by health care quality. Defined treatment and quality outcome measures resulting in standardized initial treatment pathways could improve the standard of care for IBD patients and subsequently reduce burden to both payer and patient by controlling the course of disease. Since control of IBD can be dependent on maintenance treatments, consideration of patient preference in the treatment pathway is warranted. ${ }^{29}$ In IBD, as in other chronic diseases, increased rates of patient adherence have been shown to be related to better disease management and improved patient outcomes. ${ }^{25}$ Increased physician-patient joint decision making, as well as proper patient treatment, could also improve the quality of patient care and reduce overall health care costs for IBD patients. ${ }^{30-33}$

Medical associations nationwide are responding to the need for more standardized treatment measures for chronic diseases. To date, 2 unique sets of metrics have been developed that focus on the assessment of IBD treatment quality. In 2011, the American Gastroenterology Association (AGA) published a set of 10 clinical performance measures using the Physician Consortium for Performance Improvement model. ${ }^{34}$ Additionally, the Crohn's and Colitis Foundation of America (CCFA) outlined 20 performance- and outcome-quality indicators in a 2013 special Clinical Guidelines article appearing in the journal Gastroenterology and Hepatology. ${ }^{27}$ The CCFA measures were developed from the RAND Appropriateness Panel methodology and were designed to assess therapeutic optimization, patient safety, remission, and quality of life.

Although these measures have been established, their impact on the quality of care received by IBD patients remains unknown. The impact of these measures on patient treatment quality is inextricably tied to the use of these measures by prescribing physicians. Further, measurement of quality in health care requires continuous measurement and assessment, necessitating establishment of intensive quality programs. Because administrative claims are a continuously updated source of medical information, they could be an asset in quality assessment; indeed, some measures, such as the Healthcare Effectiveness Data and Information Set measures, are designed for administrative claims. Therefore, the goal of this study was to define and calculate several of the AGA and CCFA quality measures with an administrative claims database to determine the feasibility of quality assessment in IBD through claims signatures. The rates of measure qualification by IBD patients are presented, as well as an assessment of the ability to calculate measures using claims.

\section{Methods}

\section{Data Source}

Study data were derived from the Optum Clinformatics DataMart database (Optuminsight Clinformatics, Eden Prairie, MN). Medical, pharmacy, and laboratory claims for members with an International Classification of Diseases, Ninth Revision, Clinical Modification (ICD-9-CM) diagnosis of IBD (555.x,556.x) during calendar years 2008 through 2012 were extracted. The AGA and CCFA quality measure sets were assessed for IBD patients during the calendar year 2011. All data were void of identifying information in compliance with the Health Insurance Portability and Accountability Act of 1996. Therefore, institutional review board approval was unnecessary for this study. Regardless, all work was carried out in accordance with The Code of Ethics of the World Medical Association.

\section{AGA Quality Measures}

The calculation of AGA measures using administrative claims required the computation of, at a minimum, the following 2 components ${ }^{34}$ :

1. Denominator statement. For each measure, the denominator consisted of the number of patients aged over 18 years with an ICD-9-CM diagnosis of IBD during the calendar year (measures \#8 and \#10 require an additional code for hospitalization) and a procedure code for an outpatient visit.

2. Numerator statement. The numerator for each measure contained a Category II Current Procedural Terminology (CPT) code designed to track a specific component of quality patient care. 
A portion of the measures had additional numerator and denominator exclusions, which were dependent on the specific aspects of treatment being assessed. Each AGA measure is designed to be calculated over the course of a calendar year; therefore, continuous, annual eligibility was imposed on all members for inclusion in analyses of these measures. As previously stated, denominator statements required multiple specifications, typically a CPT code and an ICD-9-CM diagnosis code; patients only qualified for these measures if the relevant codes appeared on the same claim line. Table 1 presents the list of AGA quality measures. Detailed measure definitions and claims logic may be found in the performance measurement guidance document online via the AGA website. ${ }^{34}$

\section{CCFA Quality Measures}

The CCFA indicators were designed for measurement via electronic medical records. Ten process and 10 outcome measures were developed. The list of CCFA quality measures also may be viewed in Table 1. For the detailed methodology underlying the development of these indicators, see Melmed and Siegel (2013). ${ }^{27}$ To be consistent with the AGA measure logic, CCFA outcomes were assessed only in those members aged more than 18 years.

\section{Quality Measure Application to Claims Data}

Neither of the 2 performance measurement sets were optimized to be calculated with administrative claims data. The requirement for Category II CPT codes, officially defined as "optional" performance measurement codes, was the primary limitation of the AGA set, which otherwise did include some information for administrative claims-based calculation. The CCFA set lacked standardized definitions and rules for administrative claims calculation. Therefore, the 2 quality measure sets were restated for application to claims data. The first step in this process involved the identification of AGA and CCFA metrics that overlapped in content, in which cases the AGA measures were adopted, since these measures included some logic for claims-based administration. Six of the CCFA performance measures (P1-P3, P5, P9-P10) were deemed similar in scope to 7 of the AGA measures (2, 4-8, 10; Table 1). These 7 AGA measures were then reexamined for applicability to a claims dataset. The remaining nonmatching AGA and CCFA measures were also reexamined for claims feasibility. In total, 6 of the AGA measures (3-8) were redefined with commonly used CPT and ICD-9-CM diagnosis codes in place of the seldom-used CPT Category II codes, with 4 measures (1-2, 9-10) being deemed possible to calculate with administrative claims (Table 1). Regarding the CCFA measures, as previously stated, 6 of these measures were absorbed by the similar AGA measures, and 9 additional measures were successfully redefined (P6, Olb, O3-O6, O8-O10; Table 1). One other measure (P7) was deemed possible for use with administrative claims data; the remaining 5 measures (P4, P8, Ola, O2, and O7) were dropped. Overall, 7 of the 10 AGA quality measures, 6 CCFA outcome measures, and a single CCFA performance measure were assessed in the current study. The final subset of the AGA and CCFA measures used in the current study are identified in Table 1. A completed list of updated CPT codes, ICD-9-CM codes, and other measurement adjustments applied to both measurement sets are shown in the Appendix (available in the online article)

\section{Patient Characteristics}

In addition to quality metrics, patient demographics were summarized from the membership table. Demographics reported included age, gender, geographic region of residence, insurance line of business, and type of benefit plan. Additionally, the Charlson Comorbidity Index, an overall measure of health, ${ }^{35}$ was calculated during the measurement year, as were the rates for a variety of other comorbidities of interest. Given that each quality measure contains specific inclusion and exclusion criteria which resulted in the creation of a unique sample for each measure, analyses of demographics included all members meeting the age and IBD diagnosis inclusion criteria during the measurement year.

\section{Analyses}

Descriptive statistics were reported for all demographic measures, including means and standard deviations (SDs) for scale variables and frequencies and proportions for categorical variables. For each of the AGA and CCFA metrics, numerator and denominator frequencies were reported. All data management and analyses were conducted using SPSS version 20 (SPSS Inc., Chicago, IL).

\section{Results}

The IBD sample characteristics are presented in Table 2. Approximately $53 \%$ of the sample was female, with a mean age of 45.1 years $(S D=13.8)$. The majority of members were residents of the southeastern (34.6\%) and Mid-American (38.5\%) regions of the United States, with the remaining members split between the Northeast (12.7\%) and the West (14.2\%). Almost all members were commercially insured (>99.9\%). Of this sample, a minority of members $(16.9 \%)$ were treated with a biologic (infliximab, adalimumab, or certolizumab). The most common comorbidities were disorders of lipid metabolism, hypertension, and osteoarthritis.

AGA and CCFA measure achievement are indicated in Table 3. Overall, there was a large degree of variability in measurement achievement, likely due to inconsistencies in how many of these services are billed. The performance measures ranged from $0.4 \%$ for AGA measure 9, prophylaxis for venous thromboembolism, to $66.9 \%$ for AGA measure 8 , testing for Clostridium difficile (C. difficile). The CCFA outcome measures 


\section{TABLE 1 Quality Measures}

Measure

Designation

AGA Measures

Measure \#1

Measure \#2

Measure \#3

Measure \#4

Measure \#5

Measure \#6

Measure \#7

Measure \#8

Measure \#9

Measure \#10
AGA

Measure
Ability to Assess in Claims

\section{CCFA Measures}

IBD: type, anatomic location, and activity all assessed IBD preventive care: corticosteroid-sparing therapy

IBD preventive care: corticosteroid-related iatrogenic injury, bone loss assessment

IBD preventive care: influenza immunization

IBD preventive care: pneumococcal immunization

Measure PI

Testing for latent TB before initiating anti-TNF therapy

Assessment of hepatitis B virus before initiating anti-TNF therapy

Testing for Clostridium difficile, inpatient measure

Prophylaxis for venous thromboembolism, inpatient measure

BD preventive care: tobacco user, screening and cessation intervention

\begin{tabular}{|c|c|c|}
\hline $\mathrm{X}$ & & Activity assessed is not available in claims \\
\hline $\mathrm{X}$ & & $*$ \\
\hline $\mathrm{X}$ & & * \\
\hline $\mathrm{X}$ & $\mathrm{X}$ & * \\
\hline $\mathrm{X}$ & $\mathrm{X}$ & $\begin{array}{l}\text { Dosing schedule is not consistent with data } \\
\text { extration period }\end{array}$ \\
\hline $\mathrm{X}$ & $\mathrm{X}$ & $*$ \\
\hline $\mathrm{X}$ & $\mathrm{X}$ & $*$ \\
\hline $\mathrm{X}$ & $\mathrm{X}$ & $*$ \\
\hline $\mathrm{X}$ & & $*$ \\
\hline $\mathrm{X}$ & $\mathrm{X}$ & $\begin{array}{l}\text { Tobacco cessation therapy is not usually } \\
\text { coded in claims }\end{array}$ \\
\hline
\end{tabular}

IF a patient with IBD is initiating anti-TNF therapy, THEN TB risk assessment should be documented, and tuberculin skin testing or interferon gamma release assay should be performed

\begin{tabular}{l|l}
\hline Measure P2 & IF a patient with IBD is initiating therapy with anti-TNF, THEN risk
\end{tabular} assessment for hepatitis B virus should be documented

\begin{tabular}{l|l}
\hline Measure P3 & IF a patient with IBD requires at least $10 \mathrm{mg}$ prednisone (or equivalent)
\end{tabular} for 16 weeks or longer, THEN an appropriately dosed steroid-sparing agent or operation should be recommended

\begin{tabular}{l|l}
\hline Measure P4 & IF a hospitalized patient with severe colitis is not improving on intrave-
\end{tabular} nous steroids within 3 days, THEN sigmoidoscopy with biopsy should be performed to exclude cytomegalovirus, AND surgical consultation should be obtained

\begin{tabular}{l|l}
\hline Measure P5 & IF a patient in whom a flare of IBD is suspected with new or worsening
\end{tabular} diarrhea, THEN the patient should undergo Clostridium difficile testing at least once

\begin{tabular}{l|l}
\hline Measure P6 & IF a patient with IBD is initiating 6 MP/AZA, THEN TPMT testing
\end{tabular} should be performed before starting therapy

\begin{tabular}{l|l}
\hline Measure P7 & IF a patient with ulcerative colitis is found to have confirmed low-grade
\end{tabular} dysplasia in flat mucosa, THEN proctocolectomy or repeat surveillance within 6 months should be offered

\begin{tabular}{l|l}
\hline Measure P8 & IF a patient with extensive ulcerative colitis or Crohn's disease involv-
\end{tabular} ing the colon has had disease for 8 to 10 years, THEN surveillance colonoscopy should be performed every 1 to 3 years

\begin{tabular}{l|l}
\hline Measure P9 & IF a patient with IBD is on immunosuppressive therapy, THEN patients
\end{tabular} should be educated about appropriate vaccinations, including (1) annual inactivated influenza, (2) pneumococcal vaccination with a 5 -year booster, and (3) general avoidance of live virus vaccines

Measure P10 $\quad$ IF a patient with Crohn's disease is an active tobacco smoker, THEN smoking cessation should be recommended, and treatment should be offered or suitable referral provided at least annually

Measure OlA Steroid use: proportion of patients with steroid-free clinical remission for $>12$ month period

Measure OlB Steroid use: proportion of patients currently taking prednisone (excluding those diagnosed within the last 112 days)

\begin{tabular}{l|l}
\hline Measure O2 & Number of days per month/year lost from school/work attributable to IBD
\end{tabular}

Measure O3 $\quad$ Number of days per year in the hospital attributable to IBD

\begin{tabular}{l|l}
\hline Measure O4 & Number of emergency room visits per year for IBD \\
\hline
\end{tabular}

Measure O5 $\quad$ Proportion of patients with malnutrition

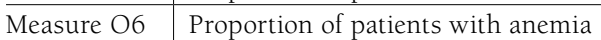

Measure 07 Proportion of patients with normal disease-targeted health-related quality of life

\begin{tabular}{l|l}
\hline Measure O8 & Proportion of patients currently taking narcotic analgesics \\
\hline
\end{tabular}

\begin{tabular}{l|l}
\hline Measure O9 & Proportion of patients with nighttime BMs or leakage \\
\hline
\end{tabular}

Measure O10 $\quad$ Proportion of patients with incontinence in the last month

\begin{tabular}{|c|c|c|}
\hline $\mathrm{X}$ & $\mathrm{X}$ & Overlap with AGA measure \\
\hline $\mathrm{X}$ & $\mathrm{X}$ & Overlap with AGA measure \\
\hline \multirow[t]{2}{*}{$\mathrm{X}$} & $\mathrm{X}$ & Overlap with AGA measure \\
\hline & $\mathrm{X}$ & $\begin{array}{l}\text { Improvement cannot be assessed in claims } \\
\text { other than by proxy }\end{array}$ \\
\hline \multirow[t]{4}{*}{$\mathrm{X}$} & $\mathrm{X}$ & Overlap with AGA measure \\
\hline & $\mathrm{X}$ & * \\
\hline & $\mathrm{X}$ & Offers are not coded in claims \\
\hline & $\mathrm{X}$ & $\begin{array}{l}\text { 1- to 3-year follow-up duration too long for } \\
\text { data extraction }\end{array}$ \\
\hline $\mathrm{X}$ & $\mathrm{X}$ & Overlap with AGA measures \\
\hline \multirow[t]{12}{*}{ X } & $\mathrm{X}$ & $\begin{array}{l}\text { Tobacco cessation therapy is not usually } \\
\text { coded in claims }\end{array}$ \\
\hline & $\mathrm{X}$ & $\begin{array}{l}\text { Remission cannot be assed in claims other } \\
\text { than by proxy }\end{array}$ \\
\hline & $\mathrm{X}$ & $*$ \\
\hline & $\mathrm{X}$ & Indirect data is not available in claims \\
\hline & $\mathrm{X}$ & * \\
\hline & $\mathrm{X}$ & * \\
\hline & $\mathrm{X}$ & Malnutrition is not usually coded in claims \\
\hline & $\mathrm{X}$ & $*$ \\
\hline & $\mathrm{X}$ & Quality of life is not available in claims \\
\hline & $\mathrm{X}$ & $*$ \\
\hline & $\mathrm{X}$ & Nocturnal occurrence is not stated in claims \\
\hline & $\mathrm{X}$ & * \\
\hline
\end{tabular}

Note: The * symbol indicates that the measure is included in this study.

$A G A=$ American Gastroenterological Association; BM= bowel movement; $C C F A=$ Crohn's and Colitis Foundation of America; $I B D=$ irritable bowel disease; $m g=m i l l i g r a m$; $T B=$ tuberculosis; $T N F=$ tumor necrosis factor; TPMT = thiopurine methyltransferase; $6 \mathrm{MP} / \mathrm{AZA}=6$-mercaptopurine and azathioprine . 


\begin{tabular}{|c|c|c|}
\hline & \multicolumn{2}{|c|}{$\mathrm{N}=22,699$} \\
\hline & Mean/Frequency & SD or \% \\
\hline \multicolumn{3}{|l|}{ Demographics } \\
\hline Female & 11,963 & 52.7 \\
\hline Age & 45.1 & $13.8(\mathrm{SD})$ \\
\hline \multicolumn{3}{|l|}{ Geographic region } \\
\hline Mid-American & 8,729 & 38.5 \\
\hline Northeast & 2,883 & 12.7 \\
\hline Southeast & 7,848 & 34.6 \\
\hline West & 3,233 & 14.2 \\
\hline \multicolumn{3}{|l|}{ Benefit plan type } \\
\hline Commercial & 22,696 & 100.0 \\
\hline Medicare/Medicaid & 3 & 0.0 \\
\hline \multicolumn{3}{|l|}{ Treatment } \\
\hline Treated with a biologic & 3,829 & 16.9 \\
\hline Infliximab & 1,788 & 7.9 \\
\hline Adalimumab & 1,648 & 7.3 \\
\hline Certolizumab & 491 & 2.2 \\
\hline \multicolumn{3}{|l|}{ Health Status } \\
\hline Charlson Comorbidity Index & 0.55 & $1.16(\mathrm{SD})$ \\
\hline \multicolumn{3}{|l|}{ Specific comorbidites } \\
\hline Disorders of lipid metabolism & 6,195 & 27.3 \\
\hline Hypertension & 5,621 & 24.8 \\
\hline Osteoarthritis & 5,317 & 23.4 \\
\hline Chronic pulmonary disease & 2,450 & 10.8 \\
\hline Depression & 2,315 & 10.2 \\
\hline Hypothyroidism & 2,054 & 9.0 \\
\hline Diabetes without complications & 1,607 & 7.1 \\
\hline Mild liver disease & 1,435 & 6.3 \\
\hline Chronic pain & 1,124 & 5.0 \\
\hline Osteoporosis & 1,064 & 4.7 \\
\hline Any malignancy & 983 & 4.3 \\
\hline \multicolumn{3}{|c|}{$\begin{array}{l}\text { Note: Sample was composed of patients aged }>18 \text { years, continuously eligible for } \\
\text { benefits for entire measurement year, and met the AGA definition of IBD during } \\
\text { the measurement year. } \\
A G A=\text { American Gastroenterological Association; IBD =irritable bowel disease; } \\
S D=\text { standard deviation. }\end{array}$} \\
\hline
\end{tabular}

were also variable with $0.6 \%$ qualifying for CCFA O10, incontinence, and $32.9 \%$ meeting requirements for CCFA Olb, utilization of prednisone. Overall, within the AGA measurement set, $C$. difficile testing in an inpatient setting (66.9\%), the use of appropriate corticosteroid-sparing therapy (51.1\%), and testing for latent tuberculosis (TB) before initiating anti-tumor necrosis factor (TNF) therapy (45.0\%) were the 3 highest achieved measures, while prednisone usage $(32.9 \%)$ and narcotic usage (24.1\%) were the 2 highest achieved CCFA outcome measures.

\section{Discussion}

IBD is a group of chronic inflammatory autoimmune diseases affecting the gastrointestinal tract. The progression of these diseases is difficult to predict and varies among individuals.
As a result, treatment pathways, although standardized, may require modification for each individual. The overall goal of treatment for IBD is to improve the patient's well being and achieve prolonged periods of disease remission, thereby preventing tissue damage and disease progression. ${ }^{36}$ The purpose of this exploratory study was to determine the feasibility of assessing the AGA and CCFA quality measures through an analysis of administrative claims data. Measures fell into 4 broad categories, including therapy for IBD (corticosteroid and narcotic therapy); laboratory testing to inform treatment decisions (influenza vaccination, latent TB, hepatitis B [Hep B], thiopurine methyltransferase [TPMT], and C. difficile testing); hospitalization (inpatient and emergency room [ER] visits); and IBD-related conditions (incontinence, venous thromboembolism prophylaxis, and anemia).

The measures assessing corticosteroid (AGA 2, 3, and CCFA OlB) and narcotic therapy (CCFA O8) were met at expected rates based on published studies. CCFA measure O1B and AGA measures 2 and 3 focus on corticosteroid use in IBD treatment, assessing use of prednisone, corticosteroid-sparing therapy, and bone loss assessments, respectively. Corticosteroids are effective for the treatment of IBD but come with notable side effects, including osteoporosis, increased risk of infection, and mood disorders. ${ }^{30,37}$ For these reasons, steroid use is recommended only for the short term or in severe cases. ${ }^{10,30,37}$ Corticosteroid-sparing therapies-which can assist in achieving remission-such as anti-TNF biologics, thiopurines, and immunomodulators, are used to control disease and reduce steroid use where possible. ${ }^{10,30}$ In the sample of patients assessed, approximately 32.9\% qualified for CCFA measure $\mathrm{OlB}$, which assesses use of prednisone for treatment of IBD. When steroid use is found to be necessary, monitoring for potential complications, such as osteoporosis, is warranted to prevent future disease. AGA measures 2 and 3 focus on the population of patients who have a 60 days' supply of corticosteroids and receive a prescription for a sparing therapy or bone loss assessment, respectively. The use of corticosteroid-sparing therapy was relatively common in the patient sample, with approximately half $(51.1 \%)$ of patients receiving some sort of sparing therapy. This rate is in line with another finding that approximately $60 \%$ of patients receiving corticosteroids for 90 days or more did not receive a sparing therapy. ${ }^{38}$ Patients with autoimmune hepatitis or inflammatory arthritis were excluded from this analysis, since these patients are more likely to require chronic prednisone use, and their disease may not be as amenable to steroid-sparing therapy. Bone loss assessments were less common than sparing therapy and were completed by $15.7 \%$ of the patient sample. A recent publication assessing adherence to this guideline in a Veterans Administration cohort found only 23\% adherence, similar to the findings reported here. ${ }^{39}$ This is a measure that is easy to accomplish and must be improved to prevent increased 


\begin{tabular}{|c|c|c|c|c|}
\hline Measure & Numerator & Denominator & $\begin{array}{l}\text { Attainment } \\
\text { Rate }(\%)\end{array}$ & Administrative Claims Limitation \\
\hline \multicolumn{5}{|l|}{ AGA Measure 2} \\
\hline Corticosteroid-sparing therapy & 897 & 1,755 & 51.1 & \\
\hline \multicolumn{5}{|l|}{ AGA Measure 3} \\
\hline Corticosteroid-related iatrogenic injury, bone loss assessment & 208 & 1,322 & 15.7 & \\
\hline \multicolumn{5}{|l|}{ AGA Measure 4} \\
\hline IBD preventive care, influenza immunization & 3,528 & 16,940 & 20.8 & \\
\hline \multicolumn{5}{|l|}{ AGA Measure 6} \\
\hline Testing for latent TB before initiating anti-TNF therapy & 317 & 704 & 45.0 & \\
\hline \multicolumn{5}{|l|}{ AGA Measure 7} \\
\hline $\begin{array}{l}\text { Assessment of hepatitis B virus before initiating anti-TNF } \\
\text { therapy }\end{array}$ & 139 & 704 & 19.7 & $\begin{array}{l}\text { Hepatitis B testing cannot be done on sero- } \\
\text { positive patients, thus excluding an unknown } \\
\text { proportion of patients. }\end{array}$ \\
\hline \multicolumn{5}{|l|}{ AGA Measure 8} \\
\hline Testing for Clostridium difficile, inpatient measure & 299 & 447 & 66.9 & \\
\hline \multicolumn{5}{|l|}{ AGA Measure 9} \\
\hline Prophylaxis for venous thromboembolism, inpatient measure & 25 & 6,810 & 0.4 & $\begin{array}{l}\text { VTE prophylaxis codes are not present in } \\
\text { claims }\end{array}$ \\
\hline \multicolumn{5}{|l|}{ CCFA Process Measure 6} \\
\hline Appropriate TPMT testing & 100 & 822 & 12.2 & $\begin{array}{l}\text { TPMT testing is only required once, and } \\
\text { claims data were only available for a short } \\
\text { period of time. }\end{array}$ \\
\hline \multicolumn{5}{|l|}{ CCFA Outcome Measure OlB } \\
\hline Proportion of patients taking prednisone & 7,071 & 21,481 & 32.9 & \\
\hline \multicolumn{5}{|l|}{ CCFA Outcome Measure O3 } \\
\hline Proportion of patients hospitalized for IBD & 2,107 & 22,699 & 9.3 & \\
\hline \multicolumn{5}{|l|}{ CCFA Outcome Measure O4 } \\
\hline Proportion of patients visiting the ER for IBD & 1,879 & 22,699 & 8.3 & \\
\hline \multicolumn{5}{|l|}{ CCFA Outcome Measure O6 } \\
\hline Proportion of patients diagnosed with anemia & 4,129 & 22,699 & 18.2 & $\begin{array}{l}\text { Anemia is not always coded, and over-the- } \\
\text { counter remedies are available and thus do } \\
\text { not appear in claims }\end{array}$ \\
\hline \multicolumn{5}{|l|}{ CCFA Outcome Measure O8 } \\
\hline Proportion of patients receiving narcotics for IBD & 5,471 & 22,699 & 24.1 & \\
\hline \multicolumn{5}{|l|}{ CCFA Outcome Measure O10 } \\
\hline Proportion of patients with fecal incontinence & 138 & 22,699 & 0.6 & Incontinence codes are not present in claims \\
\hline
\end{tabular}

morbidity for IBD patients. Also, because it is relatively easy to capture presence of a bone loss assessment in an administrative claims database, the rate of $15.7 \%$ is likely to be representative of the rates of testing. ${ }^{39}$ The last measure in the IBD therapy category met at the expected rate was CCFA O8, which assessed narcotic use for the treatment of IBD. Narcotic usage for IBD is not recommended because of adverse effects, yet the use of narcotics by IBD patients to manage severe pain is relatively common. ${ }^{40}$ For this study, narcotic prescriptions associated with an IBD office visit or surgical procedure were included in the calculation of CCFA measure O8, with 24.1\% of patients qualifying for this measure. This finding is consistent with other studies that report rates of narcotic use in IBD patients from $13.1 \%$ to $27.7 \%$. $^{41,42}$
The measures falling into the broad category of testing and vaccination were met at varying rates (12.2\%-66.9\%). The measure met by the highest percentage of patients (66.9\%) was AGA measure 8, which assesses testing for $C$. difficile at inpatient admissions. Due to their immunosuppressed status, IBD patients are at an increased risk of $C$. difficile infection compared with the general population; approximately $10 \%$ of IBD patients will develop a $C$. difficile infection during their lifetime. ${ }^{43}$ Infection can result in a dramatically increased use of health care resources in addition to the increase in morbidity, mortality, and worsened long-term prognosis. ${ }^{43,44}$ Because of the similarity of symptoms between IBD flares and $C$. difficile infection, testing is recommended for new IBD patients, as well as individuals experiencing flares or slow 
treatment progression, in order to allow for proper treatment of disease (e.g., IBD flare or C. difficile infection). ${ }^{44}$ For these reasons, prompt testing for $C$. difficile, especially in the inpatient setting, is necessary to ensure quality treatment leading to proper treatment of patient illness and decreased cost of care. This finding of $66.9 \%$ measure attainment indicates that $C$. difficile testing is ordered for the majority of inpatient hospital admissions where the patient presents with symptoms of a potential infection. However, it should be noted that the timing of the testing during the hospital stay cannot be determined from claims analysis.

Thiopurines are immunosuppressants used as a steroidsparing therapy to maintain remission of IBD symptoms. ${ }^{10}$ Genetic testing for TPMT, an enzyme involved in metabolism of mercaptopurine, can be used to determine if the patient is a good candidate for thiopurine therapy, since 3\%-14\% of the population have a genetic mutation in a TPMT allele. ${ }^{45}$ Although effective, the dose of these medications must be optimized for each patient to reduce the risk of leucopenia, which is partially dependent upon individual metabolism. ${ }^{46}$ In the current study, only $12.2 \%$ of eligible patients (patients started on a new prescription of thiopurine) were tested for TPMT within 6 months prior to initiation of therapy. ${ }^{46}$ Although TPMT testing has been found to be cost-effective, the U.S. Food and Drug Administration does not require TPMT testing prior to thiopurine therapy; however, the practice of TPMT testing has been increasing since availability of testing in 1992.46,47 It is recommended that this inexpensive and accurate test be performed on all patients prior to thiopurine initiation. ${ }^{48-50}$ Since TPMT testing is a genetic test, and only needs to be performed once in a lifetime, the 1 year assessed in this study would not be expected to yield an accurate assessment of overall TPMT testing rates. Accordingly, the low rate of TPMT testing reported here is likely due to a combination of physician practices and the use of administrative claims data in calculation.

Anti-TNF biologics have proven effective in managing IBD but result in further immunosuppression, leaving patients vulnerable to viral and bacterial infection..51,52 Therefore, determination of the patient's Hep B or TB status before the initiation of treatment is recommended in order to reduce potential complications. AGA measures 6 and 7 assess the prevalence of TB or Hep B testing prior to initiation of antiTNF therapy, respectively. AGA measure 6 was met by $45.0 \%$ of patients, while AGA measure 7 was met by only $19.7 \%$. Both of these rates are below the recommended guidelines for testing. The low rates of measure achievement may again be partly attributed to administrative claims as the data source. Since the measures require patients who are newly initiating anti-TNF therapy, the sample size for these measures was low for the single measurement year assessed. Further, TB testing is a routine test and may therefore be subject to code bundling or may not be billed by physicians at all. The lack of complete laboratory data may also be a hindrance in calculating these measures. Hep B testing was determined by use of CPT codes for Hep B vaccination, which was necessary because of the lack of laboratory data. Only those patients with negative Hep B serology are eligible for vaccination; therefore, the 19.7\% measure rate observed does not account for testing of patients who may have been ineligible. Similar to AGA measures 6 and 7 , the rate of achievement for AGA measure 4, influenza vaccination, was low (20.8\%). Because of immunosuppression associated with IBD, patients are advised to obtain an influenza vaccination to prevent infection. ${ }^{28,51,52}$ In the 2011 flu season, $43 \%$ of the general population received an influenza vaccination, notably higher than the $20.8 \%$ seen in this high-risk IBD sample. ${ }^{53}$ Once again, the low rates of measure achievement observed here may be because of the usage of out-of-network or workplace influenza vaccination programs, patient refusal, allergy (which is difficult to obtain from claims data), claim bundling, and/or failure to submit a claim.

Two measures were achieved by less than $1 \%$ of the patient sample-AGA 9 (inpatient prophylaxis for venous thromboembolism [VTE]) and CCFA O10 (rate of patient fecal incontinence). IBD patients are at a 3-fold increased risk for VTE; this relative risk is even higher during periods of disease flare. ${ }^{54}$ As a result, IBD patients should be given blood thinners or compression garments as prophylaxis for inpatients. ${ }^{54}$ Although it is known that VTE prophylaxis for IBD is not fully in compliance with guidelines, leading to calls for increased VTE prophylaxis in treating the IBD community, the measure rate of $0.4 \%$ is far too low to be accurate..$^{54}$ Other studies have reported rates of VTE prophylaxis of at least $50 \%$, and surveys conducted on IBD-treating physicians estimate that at least one third of physicians would give VTE prophylaxis. ${ }^{55-58}$ One conclusion is that it is infeasible to measure this indicator using administrative claims. The lack of relevant billing codes is likely because of inpatient billing procedures, which may use code bundling or other practices, obscuring the actual rate of measure achievement. CCFA outcome measure O10, which assesses the rate of patient fecal incontinence and was achieved by $0.6 \%$ of patients, is also deemed immeasurable in administrative claims data. The prevalence of fecal incontinence in the IBD population is difficult to estimate in general, let alone in an administrative claims database, in part because of the personal and embarrassing subject matter. Although ICD9-CM codes for fecal incontinence are available for use, they are rarely found in administrative claims. Survey studies conducted on the IBD population estimate rates of incontinence of approximately 67\%; the general population has an estimated incontinence rate of $0.4 \%-18 \%$, indicating that the finding of $0.5 \%$ in an IBD population is simply inaccurate ${ }^{59,60}$ The extremely low rate calculated in this study is indicative of the sensitive nature of facets of IBD, as well as the lack of coding for certain symptoms in medical claims. 
Two of the remaining measures-CCFA measures $\mathrm{O} 3$ and O4-assessed rates of hospitalization and ER visits for IBD, respectively. For both measures, qualification was based on the presence of a hospital or ER claim tied to an IBD-related diagnosis or procedure code (see the Appendix for complete definition, available in online article). In the sample evaluated, 9.3\% of patients qualified for CCFA measure O3, and 8.3\% qualified for CCFA measure O4 during the measurement year. Comparison of these rates with the total rates of hospitalization (17.6\% of the sample) and ER visits (12.1\% of the sample) reveals that the majority of hospital admissions (52.8\%) and ER visits $(68.6 \%)$ can be tied directly to patients having IBD.

Finally, CCFA measure O6 looked at the proportion of patients with an anemia diagnosis. Anemia is the most common complication of IBD, occurring in approximately one third of patients, and can have a notable effect on the patient's quality of life because of increased hospitalizations ${ }^{61}$ Approximately $18 \%$ of the eligible sample presented with an ICD-9-CM diagnosis code for anemia during the measurement year. This rate is lower than the estimated one third of IBD patients affected in other studies. ${ }^{61}$ The low prevalence of anemia may be a result of the availability of over-the-counter iron supplements, which do not require a prescription and therefore do not generate a pharmacy claim.

\section{Limitations}

There were a number of limitations in the current study. Although administrative claims databases can provide access to large sample sizes and can also be adapted to answer a variety of health outcomes research questions, coding inconsistencies across providers, general coding mistakes, and the dearth of clinical outcomes are some of their well-known inadequacies. ${ }^{62-64}$ Inexpensive laboratory tests and minor medical procedures may be subject to code bundling or the failure to submit a claim at all, artificially decreasing some of the measure counts. The lack of complete laboratory data may also be a hindrance in calculating these measures, especially for the measures assessing Hep B and TB, requiring some measure redesign for feasibility. Regarding AGA measure 8 in particular (inpatient $C$. difficile testing), in addition to using the standard laboratory tests to determine the administration of $C$. difficile toxin testing (CPT codes 87230, 87234, and 87449), patients with inpatient diagnosis codes for either $C$. difficile intestinal infection (008.45) or infectious diarrhea (009.1, 009.2, or 009.3) were also assumed to have received the appropriate testing. This may overestimate the true rate of achievement of this measure, but a previous study demonstrated a high concordance rate between $C$. difficile assay results and the presence of the 008.45 diagnosis code.$^{65} \mathrm{~A}$ final limitation was the sample, which consisted solely of commercially insured health plan members. It is unknown how results may generalize to members of Medicare, Medicaid, or to the uninsured.

\section{Conclusions}

This is the first examination of the AGA and CCFA quality measures assessed through administrative claims data. Rates of measure achievement were highly variable and ranged from $0.4 \%$ to $66.9 \%$. The measures achieved at lower rates are likely a reflection of the inherent difficulty and limitations using claims data. Future studies should examine additional ways to adapt such measures to claims data, which are becoming increasingly more commonplace in health outcomes studies. ${ }^{66}$ Additionally, it is presently unclear if increased measure attainment translates into genuine health care quality improvement and/or decreased health care costs. Further studies are needed to validate current findings, in addition to understanding whether attainment of these measures translates into better overall health or IBD-related outcomes.

\section{Authors}

JOSEPH TKACZ, MS, is Director of Analytics; BRENNA L. BRADY, PhD, is Project Director; and CHARLES RUETSCH, PhD, is President, Health Analytics, Columbia, Maryland. ROXANNE MEYER, PharmD, is Manager, Health Economics and Outcomes Research, and JENNIFER H. LOFLAND, PharmD, MPH, PhD, is Director, Ophthalmology Market Access Leader, Janssen Scientific Affairs, Horsham, Pennsylvania. NAYANTARA COELHO-PRABHU, MBBS, is Physician, Department of Gastroenterology and Hepatology, Mayo Clinic, Rochester, Minnesota.

AUTHOR CORRESPONDENCE: Joseph Tkacz, MS, Health Analytics, 9200 Rumsey Rd., Ste. 215, Columbia, MD 21045. Tel.: 410.997.3314; Fax: 410.997.4545; E-mail: joseph.tkacz@healthanalytic.com.

\section{DISCLOSURES}

Janssen Scientific Affairs funded this study. Meyer and Lofland are employees of Janssen Scientific Affairs and own stock in Johnson \& Johnson. Tkacz, Brady, and Ruetsch are employees of Health Analytics, which received research support from Janssen Scientific Affairs to conduct this study, a small portion of which was paid to Coelho-Prabhu to serve as a consultant.

Study concept and design were created by Meyer, Lofland, Ruetsch, and Coelho-Prabhu. Tkacz collected the data, with data interpretation performed by Tkacz and Brady, along with Coelho-Prabhu. The manuscript was written and revised primarily by Tkacz and Brady, with assistance from the other authors.

\section{ACKNOWLEDGMENTS}

The authors would like to thank Sharon Patton for her support in identifying relevant medical procedural and diagnostic billing codes, which were essential for application of the AGA and CCFA measurement sets to the claims database. 


\section{REFERENCES}

1. Hanauer SB. Inflammatory bowel disease: epidemiology, pathogenesis, and therapeutic opportunities. Inflamm Bowel Dis. 2006;12(Suppl 1):S3-9.

2. Baumgart DC, Sandborn WJ. Inflammatory bowel disease: clinical aspects and established and evolving therapies. Lancet. 2007;369(9573):1641-57.

3. Cosnes J, Gower-Rousseau C, Seksik P, Cortot A. Epidemiology and natural history of inflammatory bowel diseases. Gastroenterology. 2011;140(6):1785-94

4. Kappelman MD, Rifas-Shiman SL, Kleinman K, et al. The prevalence and geographic distribution of Crohn's disease and ulcerative colitis in the United States. Clin Gastroenterol Hepatol. 2007;5(12):1424-29.

5. Loftus EV Jr. Clinical epidemiology of inflammatory bowel disease: incidence, prevalence, and environmental influences. Gastroenterology. 2004;126(6):1504-17.

6. Leone V, Chang EB, Devkota S. Diet, microbes, and host genetics: the perfect storm in inflammatory bowel diseases. J Gastroenterol. 2013;48(3):315-21.

7. Ventham NT, Kennedy NA, Nimmo ER, Satsangi J. Beyond gene discovery in inflammatory bowel disease: the emerging role of epigenetics. Gastroenterology. 2013;145(2):293-308.

8. Jostins L, Ripke S, Weersma RK, et al. Host-microbe interactions have shaped the genetic architecture of inflammatory bowel disease. Nature. 2012;491(7422):119-24.

9. Baumgart DC, Carding SR. Inflammatory bowel disease: cause and immunobiology. Lancet. 2007;369(9573):1627-40.

10. Hanauer SB, Kornbluth AA, Messick J, Rubin DT, Sandborn WJ, Sands BE. Clinical scenarios in IBD: optimizing the use of conventional and biologic agents. Inflamm Bowel Dis. 2010;16(Suppl 1):S1-11.

11. Lichtenstein GR, Hanauer SB, Sandborn WJ; Practice Parameters Committee of American College of Gastroenterology. Management of Crohn's disease in adults. Am J Gastroenterol. 2009;104(2):465-83.

12. Kornbluth A, Sachar DB; Practice Parameters Committee of the American College of Gastroenterology. Ulcerative colitis practice guidelines in adults: American College of Gastroenterology, Practice Parameters Committee. Am J Gastroenterol. 2010;105(3):501-23.

13. Bryant RV, Winer S, Travis SP, Riddell RH. Systematic review: histological remission in inflammatory bowel disease. Is "complete" remission the new treatment paradigm? An IOIBD initiative. J Crohns Colitis. 2014;8(12):1582-97.

14. Clarke K, Regueiro M. Stopping immunomodulators and biologics in inflammatory bowel disease patients in remission. Inflamm Bowel Dis. 2012;18(1):174-79.

15. Peyrin-Biroulet L, Lémann M. Review article: remission rates achievable by current therapies for inflammatory bowel disease. Aliment Pharmacol Ther. 2011;33(8):870-79.

16. Langholz E, Munkholm P, Davidsen M, Binder V. Course of ulcerative colitis: analysis of changes in disease activity over years. Gastroenterology. 1994:107(1):3-11

17. Munkholm P, Langholz E, Davidsen M, Binder V. Disease activity courses in a regional cohort of Crohn's disease patients. Scand J Gastroenterol. 1995;30(7):699-706.

18. Park KT, Bass D. Inflammatory bowel disease-attributable costs and cost-effective strategies in the United States: a review. Inflamm Bowel Dis. 2011;17(7):1603-09.

19. Kappelman MD, Rifas-Shiman SL, Porter CQ, et al. Direct health care costs of Crohn's disease and ulcerative colitis in U.S. children and adults. Gastroenterology. 2008;135(6):1907-13.

20. Gibson TB, Ng E, Ozminkowski RJ, et al. The direct and indirect cost burden of Crohn's disease and ulcerative colitis. J Occup Environ Med. 2008:50(11):1261-72.
21. Graff LA, Walker JR, Bernstein CN. Depression and anxiety in inflammatory bowel disease: a review of comorbidity and management. Inflamm Bowel Dis. 2009;15(7):1105-18.

22. Longobardi T, Jacobs P, Bernstein CN. Work losses related to inflammatory bowel disease in the United States: results from the National Health Interview Survey. Am J Gastroenterol. 2003;98(5):1064-72.

23. Centers for Disease Control and Prevention. An expensive disease without a cure. Available at: http://www.cdc.gov/ibd/pdf/inflammatory-boweldisease-an-expensive-disease.pdf. Accessed September 22, 2015.

24. Gunnarsson C, Chen J, Rizzo JA, Ladapo JA, Naim A, Lofland JH. The employee absenteeism costs of inflammatory bowel disease: evidence from US National Survey Data. J Occup Environ Med. 2013;55(4):393-401.

25. Kane S, Huo D, Aikens J, Hanauer S. Medication nonadherence and the outcomes of patients with quiescent ulcerative colitis. Am J Med. 2003;114(1):39-43

26. Mawdsley JE, Rampton DS. Psychological stress in IBD: new insights into pathogenic and therapeutic implications. Gut. 2005;54(10):1481-91.

27. Melmed GY, Siegel CA. Quality improvement in inflammatory bowel disease. Gastroenterol Hepatol (NY). 2013;9(5):286-92.

28. Sands BE. From symptom to diagnosis: clinical distinctions among various forms of intestinal inflammation. Gastroenterology. 2004;126(6):1518-32.

29. Ediger JP, Walker JR, Graff L, et al. Predictors of medication adherence in inflammatory bowel disease. Am J Gastroenterol. 2007;102(7):1417-26.

30. Carter MJ, Lobo AJ, Travis SP; IBD Section, British Society of Gastroenterology. Guidelines for the management of inflammatory bowel disease in adults. Gut. 2004;53(Suppl 5):V1-16.

31. Ghosh S, Mitchell R. Impact of inflammatory bowel disease on quality of life: results of the European Federation of Crohn's and Ulcerative Colitis Associations (EFCCA) patient survey. J Crohns Colitis. 2007;1(1):10-20.

32. Sewitch MJ, Abrahamowicz M, Barkun A, et al. Patient nonadherence to medication in inflammatory bowel disease. Am J Gastroenterol. 2003;98(7):1535-44.

33. Goldring AB, Taylor SE, Kemeny ME, Anton PA. Impact of health beliefs, quality of life, and the physician-patient relationship on the treatment intentions of inflammatory bowel disease patients. Health Psychol. 2002;21(3):219-28.

34. American Gastroenterological Association. Adult inflammatory bowel disease physician performance measure set. Revised October 26, 2011. Available at: http://www.gastro.org/practice/quality-initiatives/IBD_ Measures.pdf. Accessed September 22, 2015.

35. Charlson ME, Pompei P, Ales KL, MacKenzie CR. A new method of classifying prognostic comorbidity in longitudinal studies: development and validation. J Chronic Dis. 1987;40(5):373-83.

36. Bernstein CN, Fried M, Krabshuis JH, et al., eds. Inflammatory bowel disease: a global perspective. World Gastroenterology Organisation Global Guidelines. June 2009. Available at: http://www.worldgastroenterology.org/ guidelines/global-guidelines/inflammatory-bowel-disease-ibd/inflammatorybowel-disease-ibd-english. Accessed September 22, 2015.

37. Katz JA. The practical use of corticosteroids in the treatment of inflammatory bowel disease. Pract Gastroenterol. 2005;29(1):14-25. Available at: http://www.practicalgastro.com/pdf/January05/Jan05Katz.pdf. Accessed September 22, 2015.

38. Reddy SI, Friedman S, Telford JJ, Strate L, Ookubo R, Banks PA. Are patients with inflammatory bowel disease receiving optimal care? Am J Gastroenterol. 2005;100(6):1357-61.

39. Khan N, Abbas AM, Almukhtar RM, Cole EB, Khan AN. Adherence and efficacy of screening for low bone mineral density among ulcerative colitis patients treated with corticosteroids. Am J Gastroenterol. 2014;109(4):572-78.

40. Long MD, Barnes EL, Herfarth HH, Drossman DA. Narcotic use for inflammatory bowel disease and risk factors during hospitalization. Inflamm Bowel Dis. 2012;18(5):869-76. 
41. Cross RK, Wilson KT, Binion DG. Narcotic use in patients with Crohn's disease. Am J Gastroenterol. 2005;100(10):2225-29.

42. Hanson KA, Loftus EV Jr, Harmsen WS, Diehl NN, Zinsmeister AR, Sandborn WJ. Clinical features and outcome of patients with inflammatory bowel disease who use narcotics: a case-control study. Inflamm Bowel Dis. 2009;15(5):772-77.

43. Binion DG. Strategies for management of Clostridium difficile infection in immunosuppressed patients. Gastroenterol Hepatol (NY). 2011;7(11):750-52.

44. Saidel-Odes L, Borer A, Odes S. Clostridium difficile infection in patients with inflammatory bowel disease. Ann Gastroenterol. 2011;24(4):263-70.

45. Payne K, Newman WG, Gurwitz D, Ibarreta D, Phillips KA. TPMT testing in azathioprine: a "cost-effective use of healthcare resources?" Personal Med. 2009;6(1):103-13.

46. Nguyen CM, Mendes MA, Ma JD. Thiopurine methyltransferase (TPMT) genotyping to predict myelosuppression risk. PLoS Curr. 2011;3:RRN1236.

47. Payne K, Newman W, Fargher E, Tricker K, Bruce IN, Ollier WE. TPMT testing in rheumatology: any better than routine monitoring? Rheumatology (Oxford). 2007;46(5):727-29.

48. Relling MV, Gardner EE, Sandborn WJ, et al. Clinical Pharmacogenetics Implementation Consortium guidelines for thiopurine methyltransferase genotype and thiopurine dosing. Clin Pharmacol Ther. 2011;89(3):387-91.

49. Ezzeldin HH, Diasio RB. Genetic testing in cancer therapeutics. Clin Cancer Res. 2006;12(14 Pt 1):4137-41.

50. Dean L. Azathioprine therapy and TPMT genotype. Medical Genetics Summaries. Updated March 18, 2013. National Center for Biotechnology Information. Bethesda, MD. Available at: http://www.ncbi.nlm.nih.gov/ books/NBK100661/. Accessed September 22, 2015.

51. Dezfoli S, Melmed GY. Vaccination issues in patients with inflammatory bowel disease receiving immunosuppression. Gastroenterol Hepatol (NY). 2012;8(8):504-12.

52. Melmed GY. Vaccination strategies for patients with inflammatory bowel disease on immunomodulators and biologics. Inflamm Bowel Dis. 2009;15(9):1410-16.

53. Centers for Disease Control and Prevention. Final state-level influenza vaccination coverage estimates for the 2010-11 season-United Sates, National Immunization Survey and Behavioral Risk Factor Surveillance System, August 2010 through May 2011. Updated December 8, 2011. Available at: http://www.cdc.gov/flu/fluvaxview/coverage_101lestimates. htm. Accessed September 22, 2015.
54. Zitomersky NL, Verhave M, Trenor CC 3rd. Thrombosis and inflammatory bowel disease: a call for improved awareness and prevention. Inflamm Bowel Dis. 2011;17(1):458-70

55. Sam JJ, Bernstein CN, Razik R, Thanabalan R, Nguyen GC. Physicians' perceptions of risks and practices in venous thromboembolism prophylaxis in inflammatory bowel disease. Dig Dis Sci. 2013;58(1):46-52.

56. Shedd GC, Franklin C, Schumacher AM, Green DE. Improving inpatient venous thromboembolism prophylaxis. South Med J. 2008;101(12):1209-15.

57. Baser O, Sengupta N, Dysinger A, Wang L. Thromboembolism prophylaxis in medical inpatients: effect on outcomes and costs. Am J Manag Care. 2012;18(6):294-302.

58. Tinsley A, Naymagon S, Trindade AJ, Sachar DB, Sands BE, Ullman TA. A survey of current practice of venous thromboembolism prophylaxis in hospitalized inflammatory bowel disease patients in the United States. J Clin Gastroenterol. 2013;47(1):el-6.

59. Ditah I, Devaki P, Luma HN, et al. Prevalence, trends, and risk factors for fecal incontinence in United States adults, 2005-2010. Clin Gastroenterol Hepatol. 2014;12(4):636-43.

60. Macmillan AK, Merrie AE, Marshall RJ, Parry BR. The prevalence of fecal incontinence in community-dwelling adults: a systematic review of the literature. Dis Colon Rectum. 2004:47(8):1341-49.

61. Stein J, Dignass AU. Management of iron deficiency anemia in inflammatory bowel disease - a practical approach. Ann Gastroenterol. 2013;26(2):104-13.

62. Curtis JR, Chastek B, Becker L, et al. Further evaluation of a claimsbased algorithm to determine the effectiveness of biologics for rheumatoid arthritis using commercial claims data. Arthritis Res Ther. 2013;15(2):404.

63. Jean S, Candas B, Belzile E, et al. Algorithms can be used to identify fragility fracture cases in physician-claims databases. Osteoporos Int. 2012;23(2):483-501.

64. Tyree PT, Lind BK, Lafferty WE. Challenges of using medical insurance claims data for utilization analysis. Am J Med Qual. 2006;21(4):269-75.

65. Dubberke ER, Reske KA, McDonald LC, Fraser VJ. ICD-9 codes and surveillance for Clostridium difficile-associated disease. Emerg Infect Dis. 2006;12(10):1576-79.

66. Riley GF. Administrative and claims records as sources of health care cost data. Med Care. 2009;47(7 Suppl 1):S51-55 
APPENDIX Descriptions and Updates for AGA and CCFA Measures

\begin{tabular}{|c|c|c|c|c|}
\hline Measure & Description & Denominator Requirements & Standard Billing Codes Applied & Additional Measure Updates \\
\hline$\overline{A G A} \# 2$ & $\begin{array}{l}\text { IBD Preventive } \\
\text { Care: } \\
\text { Corticosteroid- } \\
\text { sparing therapy }\end{array}$ & $\begin{array}{l}\text { All patients } 18 \text { years and older who are } \\
\text { continuously eligible for the entire measure- } \\
\text { ment year with a diagnosis of inflammatory } \\
\text { bowel disease. CPT service codes: } 99201 \text {, } \\
\text { 99202, 99203, 99204, 99205, 99212, } 99213 \text {, } \\
\text { 99214, 99215, 99241, 99242, 99243, } 99244, \\
99245,99251,99252,99253,99254,99255, \\
\text { 99354, 99355, 99356, 99357, G0406, } \\
\text { G0407, G0408, G0425, G0426, G0427 AND } \\
\text { ICD-9-CM diagnosis codes: 555, } 556 \text {. }\end{array}$ & & $\begin{array}{l}\text { Patients with a diagnosis of } \\
\text { autoimmune hepatitis and } \\
\text { inflammatory arthritis within } \\
6 \text { months of initiating steroid } \\
\text { therapy were excluded from } \\
\text { the denominator, as were any } \\
\text { patient receiving corticosteroid } \\
\text { injections. }\end{array}$ \\
\hline$\overline{A G A} \# 3$ & $\begin{array}{l}\text { IBD Preventive } \\
\text { Care: Bone loss } \\
\text { assessment due } \\
\text { to steroids }\end{array}$ & 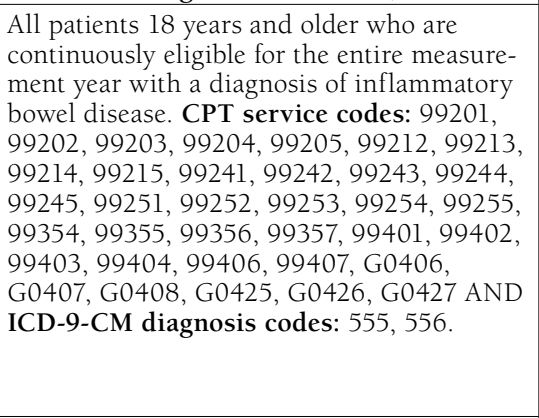 & $\begin{array}{l}\text { Tests for bone loss include: } \\
\text { DEXA - CPT codes: } \\
77080 \text { - 1+ site; axial skeleton } \\
77081 \text { - 1+ site; appendicular skeleton } \\
77082 \text { - 1+ site; vertebral fracture assessment } \\
\text { QCT (Quantitative Computed Tomography) } \\
77078 \text { - CT bone mineral study 1+ site; axial } \\
\text { skeleton } \\
77089 \text { - CT bone mineral study 1+ site, } \\
\text { appendicular skeleton } \\
\text { Ultrasound Densitometry } \\
76977 \text { - Ultrasound bone density measure- } \\
\text { ment and interpretation; axial skeleton }\end{array}$ & $\begin{array}{l}\text { The bone loss assessment } \\
\text { should occur any time within } \\
1 \text { year following the termina- } \\
\text { tion of corticosteroid therapy } \\
\text { or during therapy. }\end{array}$ \\
\hline$\overline{\mathrm{AGA} \# 4}$ & $\begin{array}{l}\text { IBD Preventive } \\
\text { Care: Influenza } \\
\text { immunization }\end{array}$ & 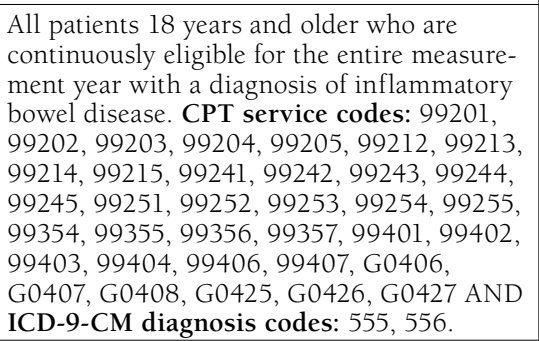 & $\begin{array}{l}\text { Influenza vaccination codes: } \\
\text { 90654, 90656, 90658, 90662, 90672, } \\
90673,90685,90686,90688\end{array}$ & \\
\hline$\overline{A G A} \# 6$ & TB testing & $\begin{array}{l}\text { All patients } 18 \text { years and older who are } \\
\text { continuously eligible for the entire measure- } \\
\text { ment year with a diagnosis of inflamma- } \\
\text { tory bowel disease. CPT service codes: } \\
\text { 99201, 99202, 99203, 99204, 99205, } 99212 \text {, } \\
\text { 99213, 99214, 99215, 99241, 99242, } 99243 \text {, } \\
\text { 99244, 99245, 99304, 99305, 99306, 99307, } \\
\text { 99308, 99309 AND ICD-9-CM diagnosis } \\
\text { codes: } 555,556 .\end{array}$ & $\begin{array}{l}\text { CPT codes: } \\
86480 \text { - Quantiferon Gold TB Test } \\
86481 \text { - TB Spot test } \\
86580 \text { - PPD Skin Test } \\
\text { ICD-9-CM codes: } \\
\text { V74.1 - special screening for TB }\end{array}$ & $\begin{array}{l}\text { Testing for latent TB prior to } \\
\text { initiating anti-TNF therapy } \\
\text { should be examined in } 6 \\
\text { months before initiating } \\
\text { therapy }\end{array}$ \\
\hline$\overline{\mathrm{AGA}} \# 7$ & Hep B & $\begin{array}{l}\text { All patients } 18 \text { years and older who are } \\
\text { continuously eligible for the entire measure- } \\
\text { ment year with a diagnosis of inflamma- } \\
\text { tory bowel disease. CPT service codes: } \\
\text { 99201, } 99202,99203,99204,99205,99212, \\
99213,99214,99215,99241,99242,99243, \\
99244,99245,99304,99305,99306,99307 \\
\text { 99308, } 99309 \text { AND ICD-9-CM diagnosis } \\
\text { codes: } 555,556 .\end{array}$ & $\begin{array}{l}\text { CPT codes: } \\
90740 \text { - Hep B vaccine for immunosup- } \\
\text { pressed patient, } 3 \text { doses, IM } \\
90743 \text { - Hep B adolescent, } 2 \text { doses, IM } \\
90744 \text { - Hep B pediatric, } 3 \text { doses, IM } \\
90746 \text { - Hep B vaccine, adult, IM } \\
90747 \text { - Hep B vaccine, immunosuppressed } \\
\text { patient, } 4 \text { doses, IM }\end{array}$ & \\
\hline$\overline{\mathrm{AGA} \# 8}$ & $\begin{array}{l}\text { C. difficile } \\
\text { testing }\end{array}$ & $\begin{array}{l}\text { All patients aged } 18 \text { years and older who are } \\
\text { continuously eligible for the measurement } \\
\text { year with a diagnosis of inflammatory bowel } \\
\text { disease hospitalized (for any reason) who } \\
\text { have refractory diarrhea at the time of hos- } \\
\text { pitalization or who develop diarrhea during } \\
\text { hospitalization. } \\
\text { CPT service codes-hospital: } 99218,99219 \text {, } \\
\text { 99220, 99224, 99225, 99226, 99251, 99252, } \\
\text { 99253, 99254, 99255, 99221, 99222, } \\
\text { 99223, 99231, 99232, 99233, 99234, 99235, } \\
\text { 99236, 99238, 99239, 99356, 99357 AND } \\
\text { ICD-9-CM diagnosis codes: } 555,556 \text { AND } \\
\text { ICD-9-CM diagnosis codes: 008.45, 009.1, } \\
\text { 009.2, 009.3. }\end{array}$ & $\begin{array}{l}\text { CPT codes: } \\
87230 \text { - C. difficile toxin test } \\
87234 \text { - C. difficile toxin A\& B II } \\
87449 \text { - C. difficile Quik Check } \\
\text { ICD-9-CM codes: } \\
008.45 \text { - C. difficile pseudomembrane colon } \\
009.1 \text { - colitis, enteritis, gastroenteritis of } \\
\text { infectious origin } \\
009.2 \text { - infectious diarrhea } \\
009.3 \text { - diarrhea of presumed infectious } \\
\text { origin }\end{array}$ & \\
\hline
\end{tabular}




\section{APPENDIX Descriptions and Updates for AGA and CCFA Measures (continued)}

\begin{tabular}{|c|c|c|c|c|}
\hline Measure & Description & Denominator Requirements & Standard Billing Codes Applied & Additional Measure Updates \\
\hline AGA \#9 & $\begin{array}{l}\text { Prophylaxis for } \\
\text { venous throm- } \\
\text { boembolism }\end{array}$ & $\begin{array}{l}\text { All patients aged } 18 \text { years and older who are } \\
\text { continuously eligible for the measurement } \\
\text { year with inflammatory bowel disease, hos- } \\
\text { pitalized for any reason. } \\
\text { CPT service codes-hospital: 99218, } 99219 \text {, } \\
\text { 99220, 99224, 99225, 99226, 99251, 99252, } \\
\text { 99253, 99254, 99255, 99221, 99222, } \\
\text { 99223, 99231, 99232, 99233, 99234, } 99235, \\
\text { 99236, 99238, 99239, 99356, 99357 AND } \\
\text { ICD-9-CM diagnosis codes: 555, 556. }\end{array}$ & $\begin{array}{l}\text { Heparin codes: } \\
\text { J1645 (drug) + } 96372 \text { (injection) } \\
\text { J1650 (drug) + } 96372 \text { (injection) } \\
\text { J1655 (drug) + } 96372 \text { (injection) } \\
\text { J1652 (drug) + } 96372 \text { (injection) } \\
\text { J1644 (drug) } \\
\text { Compression garments: } \\
\text { E0650, E0651, E0652, E0675, E0676 }\end{array}$ & \\
\hline CCFA P6 & TPMT testing & $\begin{array}{l}\text { All patients } 18 \text { years and older who are } \\
\text { continuously eligible for the entire measure- } \\
\text { ment year with a diagnosis of inflammatory } \\
\text { bowel disease. CPT service codes: } 99201 \text {, } \\
\text { 99202, 99203, 99204, 99205, 99212, 99213, } \\
99214,99215,99241,99242,99243,99244, \\
\text { 99245, 99251,99252,99253,99254, } 99255 \text {, } \\
\text { 99354, 99355, 99356,99357, G0406, } \\
\text { G0407, G0408, G0425, G0426, G0427 } \\
\text { AND ICD-9-CM diagnosis codes: 555, } 556 \text {. } \\
\text { Also must initiate be initiating 6 MP/AZA } \\
\text { therapy, defined as a 180-day 6MP/AZA- } \\
\text { naive period preceding earliest fill date. }\end{array}$ & $\begin{array}{l}82657 \text { - TPMT (thiopurine } \\
\text { S-methyltransferase) enzyme activity in } \\
\text { peripheral red blood cells }\end{array}$ & $\begin{array}{l}\text { TPMT testing should be } \\
\text { assessed any time during the } \\
6 \text { months preceding the initia- } \\
\text { tion of 6MP/AZA therapy. }\end{array}$ \\
\hline CCFA Olb & $\begin{array}{l}\text { Prednisone } \\
\text { usage }\end{array}$ & $\begin{array}{l}\text { All patients } 18 \text { years and older who are } \\
\text { continuously eligible for the entire measure- } \\
\text { ment year with a diagnosis of inflammatory } \\
\text { bowel disease. CPT service codes: } 99201 \text {, } \\
\text { 99202, 99203, 99204, 99205, 99212, 99213, } \\
\text { 99214, 99215, 99241, 99242, 99243, 99244, } \\
\text { 99245, 99251, 99252, 99253, 99254, } 99255, \\
\text { 99354, 99355, 99356, 99357, G0406, } \\
\text { G0407, G0408, G0425, G0426, G0427 AND } \\
\text { ICD-9-CM diagnosis codes: 555, 556. }\end{array}$ & & $\begin{array}{l}\text { Patients reciving budesonide } \\
\text { (ENTOCORT) were included } \\
\text { in this calculation, as it is a } \\
\text { prednisone derivative. }\end{array}$ \\
\hline CCFA O3 & $\begin{array}{l}\text { Hospitalized for } \\
\text { IBD }\end{array}$ & 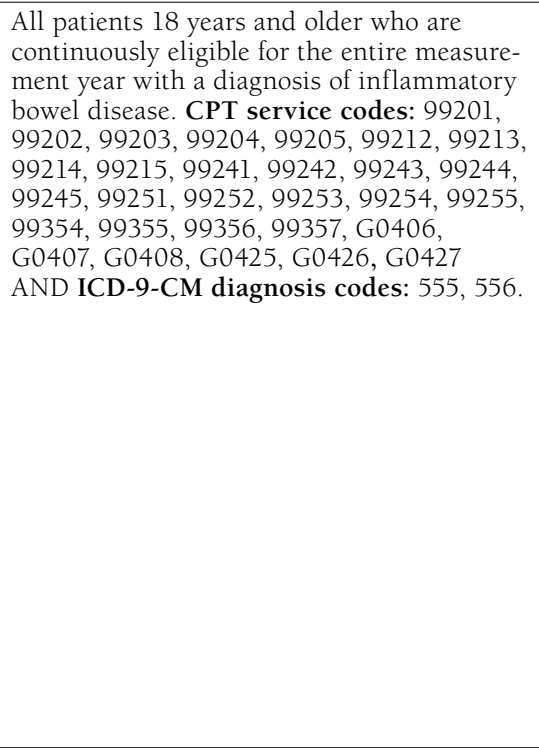 & & $\begin{array}{l}\text { Hospitalization was deemed } \\
\text { IBD-related if an inpatient } \\
\text { claim (1) carried any of the } \\
\text { following diagnoses: IBD, kid- } \\
\text { ney stones, abdominal pain or } \\
\text { colon cancer; (2) a procedure } \\
\text { code for bowel incision, other } \\
\text { abdominal or bowel surgery, } \\
\text { complete colectomy, fistula } \\
\text { repair, ostomy creation, partial } \\
\text { colectomy, colonoscopy, flexible } \\
\text { sigmoidoscopy, pouchoscopy, } \\
\text { ileoscopy, or upper endoscopy; } \\
\text { or (3) carried any of the follow- } \\
\text { ing diagnoses, accompanied } \\
\text { by any medical encounter with } \\
\text { an IBD diagnosis code within } \\
\text { the } 3 \text { months preceding or } \\
\text { following the visit: diarrhea, } \\
\text { GI bleeding, bowel obstruc- } \\
\text { tion, ileus, nausea/vomiting, } \\
\text { bloating, malnutrition, dehy- } \\
\text { dration, acute renal failure, } \\
\text { kidney injury, pancreatitis, or } \\
\text { hepatitis. }\end{array}$ \\
\hline CCFA O4 & ER visit for IBD & $\begin{array}{l}\text { All patients } 18 \text { years and older who are } \\
\text { continuously eligible for the entire measure- } \\
\text { ment year with a diagnosis of inflammatory } \\
\text { bowel disease. CPT service codes: } 99201 \text {, } \\
\text { 99202, 99203, 99204, 99205, 99212, 99213, } \\
\text { 99214, 99215, 99241, 99242, 99243, } 99244, \\
\text { 99245, 99251, 99252, 99253, 99254, } 99255 \text {, } \\
\text { 99354, 99355, 99356, 99357, G0406, } \\
\text { G0407, G0408, G0425, G0426, G0427 AND } \\
\text { ICD-9-CM diagnosis codes: 555, 556. }\end{array}$ & & $\begin{array}{l}\text { Same logic as meausre CCFA } \\
\text { O3 but applied to claims for an } \\
\text { ER visit. }\end{array}$ \\
\hline
\end{tabular}




\section{APPENDIX Descriptions and Updates for AGA and CCFA Measures (continued)}

\begin{tabular}{|c|c|c|c|c|}
\hline Measure & Description & Denominator Requirements & Standard Billing Codes Applied & Additional Measure Updates \\
\hline CCFA O6 & $\begin{array}{l}\text { Patients with } \\
\text { anemia }\end{array}$ & $\begin{array}{l}\text { All patients } 18 \text { years and older who are } \\
\text { continuously eligible for the entire measure- } \\
\text { ment year with a diagnosis of inflammatory } \\
\text { bowel disease. CPT service codes: } 99201 \text {, } \\
\text { 99202, 99203, 99204, 99205, 99212, } 99213 \text {, } \\
\text { 99214, 99215, 99241,99242, 99243, } 99244 \text {, } \\
\text { 99245, 99251,99252, 99253, 99254, } 99255 \text {, } \\
\text { 99354, 99355, 99356, 99357, G0406, } \\
\text { G0407, G0408, G0425, G0426, G0427 AND } \\
\text { ICD-9-CM diagnosis codes: 555, 556. }\end{array}$ & $\begin{array}{l}\text { ICD-9-CM diagnosis codes for } 280 . x \text { and } \\
285 . x\end{array}$ & \\
\hline CCFA O 8 & $\begin{array}{l}\text { Receiving } \\
\text { narcotics for } \\
\text { IBD }\end{array}$ & $\begin{array}{l}\text { All patients } 18 \text { years and older who are } \\
\text { continuously eligible for the entire measure- } \\
\text { ment year with a diagnosis of inflammatory } \\
\text { bowel disease. CPT service codes: } 99201 \text {, } \\
\text { 99202, 99203, 99204, 99205, 99212, 99213, } \\
\text { 99214, 99215, 99241, 99242,99243, } 99244, \\
\text { 99245, 99251,99252, 99253, 99254, } 99255 \text {, } \\
\text { 99354, 99355, 99356, 99357, G0406, } \\
\text { G0407, G0408, G0425, G0426, G0427 AND } \\
\text { ICD-9-CM diagnosis codes: 555, } 556 \text {. }\end{array}$ & & $\begin{array}{l}\text { Narcotic fill (American } \\
\text { Hospital Formulary Service } \\
\text { Classification code 280808, } \\
28080800,280812 \text {, or } \\
28081200 \text { ) within 1 week of a } \\
\text { medical encounter (1) carry- } \\
\text { ing a diagnosis for IBD, kidney } \\
\text { stones, abdominal pain, or } \\
\text { colon cancer; (2) carrying } \\
\text { a procedure code for bowel } \\
\text { incision, other abdominal or } \\
\text { bowel surgery, complete col- } \\
\text { ectomy, fistula repair, ostomy } \\
\text { creation, partial colectomy, } \\
\text { colonoscopy, flexible sigmoid- } \\
\text { oscopy, pouchoscopy, ileos- } \\
\text { copy, or upper endoscopy; or } \\
\text { (3) a visit to a colorectal sur- } \\
\text { geon (provider category codes } \\
0422,0423,0424,0425,1141 \text {, } \\
\text { 2632, 2987, 3832, or 3973). }\end{array}$ \\
\hline CCFA OlO & Incontinence & $\begin{array}{l}\text { All patients } 18 \text { years and older who are } \\
\text { continuously eligible for the entire measure- } \\
\text { ment year with a diagnosis of inflammatory } \\
\text { bowel disease. CPT service codes: } 99201 \text {, } \\
\text { 99202, 99203, 99204, 99205, 99212, 99213, } \\
\text { 99214, 99215, 99241, 99242, 99243, } 99244, \\
\text { 99245, 99251, 99252, 99253, 99254, } 99255 \text {, } \\
\text { 99354, 99355, 99356, 99357, G0406, } \\
\text { G0407, G0408, G0425, G0426, G0427 AND } \\
\text { ICD-9-CM diagnosis codes: } 555,556 \text {. }\end{array}$ & ICD-9-CM diagnosis codes for 787.6 & \\
\hline
\end{tabular}

AGA = American Gastroenterological Association; CCFA =Crohn's and Colitis Foundation of America; CPT = Current Procedural Terminology; ER=emergency room; $G I=$ gastrointestinal; Hep $B=$ hepatitis $B ; I B D=$ irritable bowel disease; ICD-9-CM=International Classification of Diseases, Ninth Revision, Clinical Modification; $I M=$ intramuscular; $T B=$ tuberculosis; $T N F=$ tumor necrosis factor; $T P M T=$ thiopurine methyltransferase; $6 \mathrm{MP} / \mathrm{AZ} \mathrm{A}=6$-mercaptopurine and azathioprine. 